\title{
TRADUCCIÓN Y PARATRADUCCIÓN EN LA LOCALIZACIÓN DE VIDEOJUEGOS
}

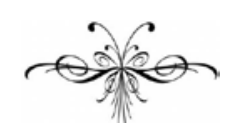

JosÉ Yuste FRÍAS

Resumen: La tecnología digital ha transformado radical y definitivamente las condiciones laborables de la traducción originando nuevas producciones audiovisuales en pantalla donde el texto, lo puramente verbal, aparece acompañado, rodeado, envuelto, prolongado, introducido y presentado por toda una producción paratextual cada vez más multimedia. El texto audiovisual y multimedia de los videojuegos se construye con ayuda de códigos de significación diferente de los puramente lingüísticos: sonidos, músicas, melodías, gestos, junto con las distintas realizaciones de la imagen (colores, símbolos, marcas, señales, fotografías, iconos, pictogramas, paisajes, planos, etc.) constituyen elementos paratextuales que resultan ser tan importantes o más que las unidades puramente lingüísticas. La lectura, interpretación y traducción para el doblaje o el subtitulado de un videojuego depende del grado de comprensión de la red de sentido tejida entre los elementos textuales, por un lado, y todos los elementos paratextuales, por otro. El éxito en la localización de un videojuego depende de una buena traducción del texto, por una parte, $\mathrm{y}$ una mejor paratraducción de los paratextos, por otra, porque texto y paratextos construyen, juntos, el imaginario del juego que se vive cuando se habita la imagen en pantalla.

Palabras clave: Videojuegos. Localización. Traducción. Paratraducción. Hipertexto.

\begin{abstract}
Digital technology has definitely and radically transformed the working conditions in translation, giving birth to new audiovisual productions where text - understood as purely verbal - is accompanied, surrounded, mixed up, prolonged, introduced and presented by an increasingly multimediatic paratextual production. The audiovisual and multimedia text of videogames is created by using different signifying codes other than the purely linguistic: sounds, music, melodies, gestures, along with the various embodiments of image (color, symbols, markings, signals, pictures, icons , pictograms, landscapes, drawings, etc.) are paratextual elements that prove to be as important - or more - as the purely linguistic units. Reading, interpreting and translating for videogame dubbing and subtitling depends on the degree of understanding of the meaning network woven between the textual elements, on the one hand, and all the paratextual elements, on the other. The successful localization of a videogame depends on a good translation of the text, on the one hand, and on an even better paratranslation of the paratexts, on the other, because text and paratexts create together the imaginary of the game one experiences on the screen.
\end{abstract}

Keywords: Videogames. Localization. Translation. Paratranslation. Hypertext. 


\section{El concepto de localización}

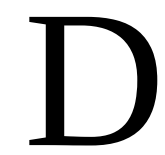
esde sus orígenes, el concepto de «localización» se ha definido siempre teniendo mucho más en cuenta el producto final que el posible texto presente en un encargo de traducción audiovisual y multimedia. Esta visión holística de la realidad del mercado profesional no sólo resulta imprescindible cuando se traduce para la pantalla sino que ha supuesto un cambio de perspectiva muy importante en los estudios sobre traducción: adentrarse en el terreno de la mercadotecnia (marketing) y dejar de centrarse, sólo y exclusivamente, en la lingüística. De hecho, en la propia raíz del término, la palabra «local», del inglés locale (Esselink, 2000: 1), hace referencia mucho más al «lugar» de los mercados («locales») para los cuales se trabaja que a los idiomas y culturas con los que se trabaja. Fue la necesidad de definir los parámetros espaciales del mercado local del país en el que se quería vender los primeros productos informáticos lo que provocó en Estados Unidos, desde finales de los años setenta y principios de los ochenta (Esselink, 2006), la creación de ficheros de configuración en los programas informáticos (software) donde había que precisar la lengua (con sus posibles variantes lingüísticas) de todos los interfaces del programa (menús, cuadros de diálogo, mensajes de error, etc.) en los cuales los detalles ortotipográficos para cada tipo de teclado (azerty o querty) no se podían dejar al azar: puntuación; uso de mayúsculas; reglas de acentuación de las palabras; reglas de interpretación de las cifras (convenciones de escritura de números, fechas y horas). Todos estos parámetros locales tenían y siguen teniendo como objetivo primordial que el software funcione perfectamente en el mercado de destino. Es la lógica comercial la que impone la creación del término de localización para que un producto se venda bien y funcione mejor. Por consiguiente, en los inicios de la actividad localizadora toda la atención se centraba no tanto sobre un texto o un documento en particular sino sobre todo un programa. El objetivo primordial de la localización era que el producto funcionase perfectamente en las manos del usuario final y no sólo que el texto le comunicase algo.

Certes, un programme, qui n’est rien d'autre qu'une série de commandes déclenchant des actions exécutées par un ordinateur, s’appuie sur une interface pour permettre à l'utilisateur de s'en servir. Certes, cette interface contient du texte présenté suivant certaines conventions qui, dans le cas des interfaces graphiques modernes, sont dictées par l'exiguïté de l'espace d'affichage et des fonctionnalités spécifiques liées à leur emplacement (le titre d'une boîte de dialogue, le texte d'un bouton ou celui d'un menu obéissent à des règles rédactionnelles différentes). Mais ce qu'il faut retenir, c'est que le contenu textuel d'une interface n'est qu'une composante de celle-ci, laquelle n'est à son tour qu'une composante du logiciel, dont la partie fondamentale est formée par des milliers de lignes de code invisibles pour l'utilisateur. La localisation d'un logiciel exige donc, par voie de conséquence mais néanmoins de façon subsidiaire, l'adaptation de l'ensemble de ses composantes aux exigences conventionnelles posées par l'environnement de l'utilisateur final. (Cancio Pastor y Belmonte, 2010: 665-666)

Bajo esta perspectiva, la traducción jamás debería confundirse con la localización ya que tan sólo constituiría una faceta de esta última. El traductor sería un eslabón de la cadena localizadora en la que se puede encontrar profesionales de la pantalla tan variados como creadores, desarrolladores, grafistas, redactores y un conjunto variopinto de especialistas y técnicos de la edición digital (Gouadec, 2003: 528-529). Pero, según Daniel Gouadec, la localización sería el súmmum de la acti- 
vidad traductora ya que el traductor no es un eslabón cualquiera de la cadena localizadora sino el mejor de todos... la pieza clave... en definitiva, el profesional mejor preparado para convertirse en el mejor localizador.

Et c'est bien là la donnée essentielle qu'il faut se garder de perdre de vue : le localiseur/localisateur est le traducteur le plus abouti avec des compétences particulières (additionnelles) le rendant apte à la pratique spécifique de la localisation. Il connaît les matériaux particuliers qui font l'objet de la localisation, il maîtrise les environnements requis, il connaît et sait gérer des partenaires nouveaux et plus présents que dans les situations habituelles de traduction. Mais il s’agit bien d'un traducteur. (Gouadec, 2003: 536)

Ahora bien, con la noción de internacionalización del producto desde su concepción (Esselink, 2003; Niosi y Tshang, 2009) y el uso de las memorias de traducción para la gestión de contenido textual, la localización ha reducido la actividad del traductor a una tarea casi automática. Una deshumanización de la tarea de traducir totalmente inaceptable para cualquier profesional con un mínimo sentido crítico. Los traductores no somos máquinas que, al reconocer ópticamente los caracteres, reemplazamos frases y segmentos textuales de forma automática, sin pensar absoluto. Los traductores somos seres humanos que traducimos el sentido interpretado de un texto gracias a la estrategia textual que se ha creado durante nuestra lectura. Anthony Pym no sólo ha llamado la atención sobre el peligro de las nuevas nociones terminológicas que, como el concepto de localización, provienen de ideologías capitalistas y globalizadoras, sino que ha promovido la necesidad de reafirmar los aspectos básicos de la competencia traductora a la hora de resistir a la deshumanización que provocan las nuevas tecnologías (Pym, 2003, 2004), sobre todo cuando estas menosprecian e infravaloran a los traductores al asegurarse de que, por ejemplo, las memorias de traducción en red no puedan pertenecer a los traductores que las crean (Pym, 2010). Cuando la tecnofilia supone un peligro para las competencias traductoras estamos a un paso de la desprofesionalización del traductor convertido en mera pieza mecánica de la máquina localizadora.

Éblouis par la technologie, les acteurs de la localisation prennent le risque d'oublier qu'ils exercent un métier de communication. Et que la communication reste une affaire humaine. (Cancio Pastor y Belmonte, 2010: 672)

Desde que el término de localización se creó para responder a la demanda de los fabricantes de productos informáticos, la «ola localizadora» (Quirion 2006: 825) se ha extendido como un tsunami para aplicarse a todos los campos de edición digital habidos y por haber: localización de webs; localización de videojuegos; localización de software; localización de dispositivos móviles; localización de productos multimedia. Carmelo Cancio Pastor y Sidney Belmonte (2010: 662) apuntan cómo resulta revelador que una de las obras de referencia sobre la localización, el libro de Bert Esselink, perdiese, en tan sólo dos años, el sustantivo software en el título de su segunda edición. De A Practicale Guide to Software Localization (1998) se pasó a A Practical Guide to Localization (2000) sin más.

La localisation n’est plus, désormais, cantonnée au seul domaine des applications informatiques. Après s'être étendue aux domaines connexes d'Internet, du multimédia et des jeux vidéo (qui, rappelons-le, ont une composante purement logicielle), elle s'applique maintenant à tous les domaines qui font appel à l'électronique pilotée: depuis le cinéma (en salle ou à domicile, pourvu qu’il soit 
numérique) jusqu’à l'édition électronique, en passant par l'électroménager grand public ou l'automobile, on trouve partout des interfaces logicielles - qu'il a fallu localiser: c'est la réalité des praticiens d'aujourd'hui. (Cancio Pastor y Belmonte, 2010: 671)

Hoy en día casi nadie parece atreverse a destronar a «la reina» del mercado de la traducción en la era digital. Al contrario, el término se ha llegado a implantar de tal forma que parece estar arrasando del mapa de los estudios sobre traducción conceptos tan tradicionales como el de «adaptación». ¿Estamos ante una nueva etiqueta para designar una actividad secular o acaso es una astuta y hábil maniobra para vender mejor (¡y más cara!) la actividad de traducir? Si la ideología de la localización está basada en la adaptación cultural, el término de localización no sería algo tan «novedoso» para hacer referencia, más o menos, a lo que siempre ha hecho referencia la traducción tradicional (Pym, 2010).

Rappelons que l'adaptation d'un produit ne représente pas en soi une nouveauté; [...] L'adaptation textuelle est séculaire, ce n'est certes pas le phénomène de la localisation qui l'a mise au monde. [...] Citons pour exemple des personnages de bande dessinée d'une revue française pour enfants qui font du vélo sans casque, mais qui, dans la version québécoise du même magazine, apparaissent désormais coiffés de cet accessoire. Une autre représentation du désir de voir sa marchandise spontanément acceptée est celle d'un concepteur français d'imageries pour enfants, qui offre depuis peu une version québécoise de sa publication la plus illustre. (Quirion 2006: 826)

La definición del término de «localización» ${ }^{1}$ nació y creció en el seno de una asociación profesional de empresas de localización creada en 1990 (LISA [Localization Industry Standards Association]) a cuya web sólo se puede acceder gracias a los historiales recogidos por Internet Archive desde el cierre de la organización el 28 de febrero de 2011. No seré yo quien niegue que no hay nada mejor que la realidad de la experiencia profesional para hacer avanzar la reflexión teórica en los estudios sobre traducción. Pero la creación de la docencia universitaria debería ser consciente de que la nueva noción de «localización» ha traído consigo que el «traductor» de toda la vida sea llamado hoy en día de formas tan eufemísticas como poco claras: «asesor lingüístico», «especialista en comunicación multilingüe», «transcreador», «teletraductor», etc. resultan ser las denominaciones de los servicios ofertados por esas compañías Languages Services Providers o de las agencias de Multilingual Copywriting Service que tanto pululan en internet. La industria que crea esta nueva terminología en lugar de llamar al pan, pan y al vino, vino, es muy dada a la creación braquigráfica de sus actividades comerciales, incluso para designarse a si misma: GILT (Globalización, Internacionalización, Localización y Traducción). El mejor ejemplo está en la abreviación creada a partir de la palabra inglesa localization que enseguida se transformó en L10N (la primera y última letras de la palabra, L y N, y el número de letras, diez, que existen entre ambas). Tal y como apunta Anthony Pym (Pym, 2010), esto explica el nombre de una de las mayores empresas de localización del mundo: Lionbridge.

\footnotetext{
${ }^{1}$ Así define LISA su término por antonomasia: «La localización implica hacer que un producto sea apropiado lingüística y culturalmente para el mercado local de destino (país/región e idioma) donde se utilizará y venderá.»
} 


\section{El concepto de hipertexto}

Los cinco tipos diferentes de localización de productos anteriormente mencionados (webs, videojuegos, software, dispositivos móviles y productos multimedia) están basados en un nuevo tipo de texto: el hipertexto. En informática, el hipertexto hace referencia a una nueva presentación de la información estrecha y tecnológicamente relacionada con el nuevo tipo de soporte digital utilizado. Mucho más concretamente, la noción de hipertexto viene a significar el modo de unión directa de informaciones diversas, ya sean de orden textual o no ${ }^{2}$, con ayuda de enlaces. Recordemos que el actual término de hipertexto ya fue utilizado, con un sentido algo diferente, en una disciplina de gran ayuda para el traductor literario: la teoría de la literatura. Así para Gérard Genette, el hipertexto designa «tout texte dérivé d'un texte antérieur par transformation simple [...] ou par transformation indirecte» (Genette, 1982: 14). Según la definición del hipertexto dada por Genette, el Ulises de James Joyce sería un hipertexto de la Odisea de Homero.

Con la llegada de la era digital, nuestra civilización está asistiendo al estallido de todos los límites del texto tradicional. Según Ducrot y Todorov, el texto se caracteriza «par son autonomie et par sa clôture» (Ducrot y Todorov, 1972: 375). Toda una definición clásica del texto que, cuando menos, resulta algo problemática con la aparición del hipertexto. En efecto, el hipertexto en Internet puede perfectamente tener tan sólo los límites aparentes de principio y fin que decida marcar el propio jugador en su sesión de juego o el internauta en su sesión de lectura. Con el hipertexto, el texto ha dejado de ser algo lineal, cerrado y estable para convertirse en algo totalmente flexible, abierto y efímero. Gracias a un interfaz que utiliza multitud de elementos esencialmente visuales e intuitivos, tales como colores e iconos, el usuario de un hipertexto puede localizar en pantalla los lugares en los que se encuentra un documento o información suplementaria y acceder a ellos directamente con tan sólo manejar adecuadamente sus pulgares en el mando de la consola o con una única presión de su dedo índice en el ratón. El desplazamiento hipertextual que supone pinchar los enlaces otorga al lector una cierta sensación de control total del objeto en la medida en que, evidentemente, el programa así lo haya querido. Tanto el mando de la consola como el ratón del ordenador resultan también ser el exacto equivalente del mando a distancia del televisor, con todo lo que ello implica para el proceso de lectura: desplazamientos hipertextuales extremadamente rápidos y caóticos, poco favorables a una sosegada lectura intensiva y más proclives a una cierta filosofía del zapping continuo, llegando a propugnar una frenética metalectura extensiva inmediata y urgente.

La no linealidad del texto digital implica una mutación en la lectura y, por consiguiente, un cambio de perspectiva que influye enormemente en los fundamentos de la teoría de la traducción (Pym, 2010). La «novedad» de los nuevos textos digitales que el traductor/localizador debe traducir para la pantalla viene dada por las características icónicas, o, mejor dicho, «picturales» inherentes a todo hipertexto (Cf. Yuste Frías, 2005: 67-75). En efecto, no solo todos los videojuegos, sino que todas las webs y, en general, todos los productos que más tarde o más temprano terminarán editados en una pantalla gracias a su estructura hipertextual siguen siempre un patrón mucho más «pictórico» que textual en su edición digital. Y ello

\footnotetext{
${ }^{2}$ La hipertextualidad también llega a la imagen ya que muchas veces, gracias a los enlaces, un simple «acercamiento» a la imagen ya sea con mando de la consola o con el puntero del ratón permite acceder a nuevas imágenes en un videojuego.
} 
hasta tal punto que el mosaico verbo-icónico ofrecido permite asimilar el texto digital a un auténtico cuadro. La «densificación icónica» resulta estar íntimamente ligada a la apariencia textual de todo recurso u objeto de la red. Texto e imagen: dos medios distintos, con formas distintas de percepción sensorial, en un mismo soporte.

La grande nouveauté (outre l'accès «en ligne» à toutes les banques de données du monde...) est l'intégration du texte, de l'image [...] sur un même support. [...] On oublie trop facilement que le texte, l'image [...] obéissent chacun à des logiques de perception et d'imagination différentes, voire antagonistes. (Breton, 1997: 146)

Las unidades verbo-icónicas de los hipertextos que encontramos hoy en los productos digitales se construyen para seducir a los posibles jugadores/lectores que detendrán así su partida/navegación durante unos minutos. La consecuencia fundamental para el traductor es que, en esta espectacularización del texto que supone el trabajo con los hipertextos, la perspectiva traductiva debe centrarse en considerar que se está ante un material esencialmente visual. En la localización, toda manipulación de una variable cualquiera de una unidad verbo-icónica que debe traducirse provocará repercusiones en el hipertexto y, consecuentemente, modificará la jugada/lectura que del hipertexto meta hará el destinatario final.

Los videojuegos son un subtipo especial dentro de la narrativa hipertextual, forman parte de la llamada «narrativa hipermedia», es decir, aquélla en la que además de texto e imagen fija se incluye otro tipo de elementos multimedia hipervinculados como el sonido, la música o la imagen en movimiento. Con la narrativa hipermedia, en los videojuegos se pasa del simple mapa de navegación del hipertexto a todo un guión multimedia. En los hipertextos de los videojuegos texto, imagen y sonido construyen unidades verbo-icono-sonoras inseparables en el proceso de localización. Si un texto siempre es un signo que debe ser leído, en los hipertextos de los videojuegos, el sonido y la imagen sólo puede provocar un recorrido de lectura si han sido adecuadamente contextualizados: el lenguaje produce primero sentido y, luego, efecto; el sonido y la imagen producen primero efecto y, luego, sentido. Los sonidos y las imágenes invitan al traductor/localizador de videojuegos a realizar un modo de lectura diferente, de carácter simbólico, que permita captar la sutil relación de estructuras simbólicas establecidas por lo sonoro y lo icónico (lo no verbal) con lo puramente verbal. El traductor/localizador de videojuegos resulta ser tan responsable de la puesta en escena de la narrativa hipermedia, de su organización sonora y visual, como el ingeniero de sonido, el músico, el creador infográfico o el técnico informático de turno. En la localización de videojuegos, el texto traducido entregado por el traductor sufre varias transformaciones en las múltiples manipulaciones a las que se le somete antes de sacar el videojuego a la venta. Se impone una metodología adecuada que permita al traductor/localizador tener la posibilidad real de un control completo de todos los elementos sonoros e icónicos que, definitivamente, van a definir el videojuego si, realmente, se quiere ofrecer al cliente un producto capaz de competir en el mercado global.

La tecnología digital ha transformado radical y definitivamente las condiciones laborables de la traducción originando nuevas producciones audiovisuales en pantalla donde el texto, lo puramente verbal, aparece acompañado, rodeado, envuelto, prolongado, introducido y presentado por toda una producción paratextual cada vez más multimedia. El texto audiovisual y multimedia de los videojuegos se cons- 
truye con ayuda de códigos de significación diferente de los puramente lingüísticos: sonidos, músicas, melodías, gestos, junto con las distintas realizaciones de la imagen (colores, símbolos, marcas, señales, fotografías, iconos, pictogramas, paisajes, planos, etc.) constituyen elementos paratextuales que resultan ser tan importantes o más que las unidades puramente lingüísticas. La lectura, interpretación y traducción para el doblaje o el subtitulado de un videojuego implica un alto grado de comprensión de la red de sentido tejida entre los elementos textuales, por un lado, y todos los elementos paratextuales, por otro. El éxito en la localización de un videojuego depende de una buena traducción del texto, por una parte, y una mejor paratraducción de los paratextos, por otra, porque texto y paratextos construyen, juntos, el imaginario del juego que se vive cuando se habita la imagen en pantalla.

\section{Los videojuegos vistos desde la noción de paratraducción}

Desde un principio, la noción de paratraducción fue acuñada para analizar el espacio y el tiempo de traducción de todo paratexto que rodea, envuelve, acompaña, prolonga, introduce y presenta el texto traducido con el fin de asegurar su existencia, su recepción y su consumo en el mundo editorial no solamente bajo la forma de libro, sino también bajo cualquier otra forma de producción editorial digitalizada (libro electrónico, CD-ROM, DVD, Sitios Web, Videojuegos, etc.). A la hora de establecer el papel de las relaciones de poder desempeñado por las distintas ideologías en la difusión y recepción de las traducciones, la paratraducción invita al traductor (sujeto que traduce y primer agente paratraductor) a leer, interpretar y paratraducir todo símbolo y toda imagen que rodea, envuelve, acompaña, prolonga, introduce y presenta al texto en los márgenes del papel o de la pantalla, en los umbrales de la traducción —au seuil de la traduction (Cf. Yuste Frías, 2010).

En una primera aproximación intentar proponer la noción de paratraducción como, simplemente, la traducción de los paratextos, no es suficiente porque tan sólo supondría una ampliación del corpus textual objeto de la mirada traductológica sin llegar a suscitar una nueva teorización. Para seguir siendo fieles a la amplitud poética propuesta por el propio Gérard Genette, sería una lástima no otorgar a la noción una mayor extensión teórica que podría ser de gran provecho para la traductología. Y es que si la traductología nunca ha dejado de estar atenta a los efectos ideológicos omnipresentes en los procesos de traducción habiendo destacado las manipulaciones que se llevan a cabo (Cf. Lefevere 1992 y Niranjana 1992), siempre lo ha hecho desde la perspectiva de los textos traducidos y sus relaciones con los originales, utilizando tan sólo muy puntualmente los paratextos. De ahí que en el Grupo de investigación Traducción \& Paratraducción (T\&P) no nos hayamos contentado con sólo importar del dominio disciplinario de la teoría de la literatura la noción de "paratexto» para aplicarla a la traductología. Hemos hecho viajar la noción de paratexto con el fin de poner a trabajar teórica y prácticamente la nueva noción de paratraducción en tres niveles metodológicos siguientes:

1. Un nivel empírico que estudia los elementos paratextuales, verbales y no verbales (provenientes de códigos semióticos como el visual y el auditivo), relacionados física o virtualmente con el texto que hay que traducir. Lo cual requiere preparar al profesional en adquirir estrategias de traducción diferentes a las 
que está acostumbrado cuando trabaja sólo y exclusivamente con el código lingüístico. Sería el nivel paratraductivo propiamente hablando.

2. Un nivel sociológico que estudia los agentes, las normas, los procedimientos y las instituciones relacionadas con el proceso traductivo y todas las fases desarrolladas. Estaríamos en un nivel protraductivo.

3. Un nivel discursivo que estudia aquellos discursos sobre la traducción que guían su funcionamiento y aseguran su papel en la sociedad. Se trata de un nivel metatraductivo.

Evidentemente no es nada nuevo estudiar estos fenómenos. La novedad de pensar la paratraducción a la hora de localizar videojuegos reside en intentar describir lo que une los tres niveles que acabo de comentar con el fin de estructurar un posicionamiento metodológico común situado alrededor de la traducción audiovisual y multimedia o, mejor dicho, en sus márgenes, siempre atento a todo lo que influye o determina el proceso de traducción y que, hasta la fecha, ha escapado del esquema tradicional de lectura adaptada por la traductología tradicional basada, única y exclusivamente, en el texto traducido y muy pocas veces en sus paratextos. La mirada paratraductológica que queremos dar en los Estudios sobre Traducción afirmaría lo siguiente: siempre hay unos márgenes en los textos, activos en tres niveles diferentes, que participan plenamente en el proceso de traducción.

Como cualquier otra producción editorial, el videojuego descansa sobre un conjunto de postulados paratextuales que hacen referencia a la manera en que se concibe la «lectura» del videojuego, su comprensión, su interpretación y, por consiguiente, la manera de jugar. De la misma forma que un libro sólo existe cuando se lee, desde el Grupo de Investigación T\&P consideramos que los videojuegos no existen como tales hasta que, dentro de la pantalla, se leen, se escuchan, se contemplan y se juegan, y, fuera de la pantalla, se prolongan, se introducen y se presentan de una determinada manera u otra. La edición de los videojuegos nos indica siempre la manera en que una sociedad concibe y regula la producción del sentido de un juego en pantalla y fuera de ella. Ahora bien, en todo proceso de localización dichas concepciones y reglas del sentido de los videojuegos pueden variar de un espacio cultural a otro y, por consiguiente, de una lengua a otra en función de determinados paratextos, es decir, en función de un determinado conjunto formado por unidades verbales y sensaciones no verbales (icónicas, sonoras y hasta táctiles) que, dentro del espacio material de la pantalla (los PERItextos), envuelven, rodean o acompañan a todo lo que se escucha o se mira en el videojuego y, fuera del espacio material de la pantalla (los EPItextos), hacen referencia al videojuego prolongándolo, introduciéndolo y presentándolo en otros espacios externos físicos y sociales virtualmente ilimitados. (Cf Yuste Frías, 2011a) 


\section{LOS PARATEXTOS Y LA PANTALLA}

Conjunto de elementos paratextuales (unidades verbales, icónicas, sonoras, entidades sonoro-icono-textuales o simples producciones materiales) que acompañan, rodean, envuelven, prolongan, introducen y presentan el texto audiovisual y multimedia en dos espacios diferentes: dentro de la pantalla y fuera de la pantalla.

\begin{tabular}{|c|c|}
\hline PERITEXTOS & EPITEXTOS \\
son los elementos paratextuales & son los elementos paratextuales \\
que acompañan, rodean y envuelven al texto & que prolongan, introducen y presentan al \\
audiovisual y multimedia & texto audiovisual y multimedia \\
DENTRO DE LA PANTALLA & FUERA DE LA PANTALLA \\
y, por consiguiente, sólo son accesibles una & y, por consiguiente, son accesibles sin ac- \\
vez activados los mecanismos de interactivi- & tivar ningún mecanismo de interactividad \\
dad entre el usuario y el producto. & entre el usuario y el producto. \\
\hline
\end{tabular}

Un traductor de videojuegos no es sólo el sujeto que traduce los textos que se van a escuchar (doblaje) o se van a leer (subtitulado) en pantalla sino también el primer agente paratraductor y, por consiguiente, el mejor localizador que debería decidir en la edición definitiva de todos y cada uno de los paratextos que acompañarán, rodearán, envolverán el videojuego en pantalla, y aquellos que lo prolongarán, introducirán y presentarán fuera de ella. En toda localización de videojuegos que se precie se impone instaurar una lógica de redes que teja vínculos de relaciones entre, por un lado, el traductor y, por otro, un gran conjunto de segundos y terceros agentes paratraductores, no traductores, propiamente hablando, desde los actores hasta el director de doblaje, pasando por el maquetador de la carátula del DVD del juego a terminar por el ingeniero de sonido, por no mencionar al propio creador del videojuego. Para el Grupo T\&P, la localización de un videojuego consiste en la traducción de sus textos y la paratraducción de sus paratextos, tanto dentro como fuera de pantalla, pensando siempre en el contexto del uso final que del producto videojuego hará el jugador de la lengua y cultura de llegada.

\section{La imagen en la localización de videojuegos}

La paratraducción de una traducción es su imagen publicitaria. L'image semble s'imposer à quiconque a affaire au paratexte (Genette, 1987: 8. Nota 1). Una de las principales consecuencias de la voluntad implícita en la noción de paratraducción de querer revalorizar el umbral, el margen desmarginalizado, es otorgar a la imagen y, en general, a todo el aspecto visual de los paratextos, la importancia que tiene en la construcción de sentido simbólico en la localización de videojuegos. Sin una buena paratraducción de todos y cada uno de los elementos paratextuales presentes en pantalla y fuera de ella, la localización de videojuegos fracasa estrepitosamente al no conseguir el éxito de ventas que se esperaba.

Leer e interpretar la imagen en la era digital, implica ser consciente de los diferentes tipos de relación que el espectador establece con la imagen en cada cultura. La lectura e interpretación de la imagen en traducción debe tener siempre en cuenta las condiciones y los efectos de su recepción en las estructuras simbólicas de la cultura de llegada. Cultivar el sentido de la mirada del traductor resulta ser esen- 
cial a la hora de leer e interpretar la imagen. Sólo aquellos paratextos icónicos cultivados por la mirada lectora e interpretativa del traductor se convierten en imagen para traducir. Es la mirada del traductor la que hace que toda imagen se constituya en espacio que debe explorarse en un encargo de traducción. Es el sentido de la mirada del traductor lo que permite desvelar los imaginarios implícitos y explícitos. Las imágenes materiales son productos culturales cuyo sentido cambia según la localización espacio-temporal. Para comprender la información aportada por una imagen hay que compartir los mismos códigos semióticos y culturales que el público a quien va dirigida, lo cual implica, en el caso de todo profesional de la traducción, poseer las competencias culturales suficientes sobre la historia y los valores sociales de la cultura de partida donde ha sido creada la imagen y de la cultura de llegada para la cual se traduce. De lo contrario, el sentido de la imagen no sólo no será leído correctamente sino que su interpretación podrá estar llena de errores.

Ahora bien, en la localización de videojuegos se suele olvidar con demasiada frecuencia que la imagen en traducción es siempre un símbolo y nunca un signo. Plantearse la imagen como signo puede parecernos lo más natural, pero, en realidad, perjudica enormemente la comprensión y la interpretación de las complejas relaciones que con la imagen se fraguan en la era digital. Concebir la imagen en traducción como signo y no como símbolo impide comprender los nuevos desafíos que plantean las formas nuevas adoptadas por la imagen en las pantallas, sobre todo, en el caso de los videojuegos. La excesiva importancia que nuestra cultura occidental ha otorgado a la palabra ha situado a la imagen a remolque de la lengua y, por consiguiente, no sólo le ha otorgado un papel secundario sino que ha supuesto la equiparación de la imagen a un tipo de signos. ¡Nada más erróneo! Pensar en la imagen en traducción como un «signo» es peligroso e insuficiente. Peligroso porque coloca la imagen a remolque de la palabra; e insuficiente porque no da cuenta de las características semióticas propias que la imagen siempre han tenido en la traducción audiovisual y multimedia. El traductor debe pensar la imagen no como un signo más sino como un elemento paratextual esencial en la institución de lo simbólico como principio de estrategia textual. La imagen en traducción debe «leerse e interpretarse» de forma simbólica porque, a diferencia del signo (caracterizado siempre por su temporalidad), la dimensión espacial de la imagen hace de ella una especie de pantalla que invita al traductor a explorarla y franquearla en busca del placer de estar «dentro» de la imagen y no sólo «frente» a la imagen. Si el traductor no consigue experimentar la sensación del placer de estar «dentro» de la imagen, la traducción de los videojuegos, por ejemplo, está condenada al mayor de los fracasos. Leer e interpretar la imagen en la era digital, implica ser consciente de los diferentes tipos de relación que el espectador establece con la imagen en cada cultura. (Cf. Yuste Frías, 2011b: 264-266).

\section{«Dentro» y no «delante» de la imagen en la localización de videojuegos}

Desde la invención del caballete en pintura, la postura que la sociedad occidental ha exaltado durante demasiado tiempo como modelo exclusivo de nuestra relación con la imagen consiste en permanecer delante de las imágenes sin más. La traducción de videojuegos implica, en cambio, la existencia de la capacidad del traductor de entrar dentro de las imágenes que desfilan en pantalla. Los Translation Studies deberían dejar de mirar las imágenes sólo y exclusivamente como «repre- 
sentaciones» y empezar a considerarlas como lo que también realmente son en la era digital: procesos de simbolización. Me explico, el uso de imágenes en traducción no tiene como único y exclusivo fin la «significación», con la imagen en traducción también se persigue construir imaginarios espacios simbólicos que se puedan explorar y transformar para dar sentido a la lectura e interpretación de quien los recorre. La realidad virtual hace posible el deseo ancestral del hombre de entrar en la imagen, de ahí el enorme éxito de los videojuegos. La base de datos de gráficos interactivos de los videojuegos puede explorarse y visualizarse en tiempo real gracias a las imágenes de síntesis tridimensionales, lo cual permite recrear la sensación de una «inmersión total» en la imagen, en un mundo tridimensional e interactivo. Lo que acabo de decir puede sonar a auténtica perogrullada, pero no ser consciente de ello suele llevar a traducciones de videojuegos que han olvidado por completo transmitir la sensación de estar bañado por la imagen en los procesos de localización. Así por ejemplo, las malas y hasta pésimas traducciones de los nombres propios de los personajes de los videojuegos suelen estar provocadas muchas veces porque el traductor no ha sabido leer e interpretar la representación icónica del personaje en cuestión desde «dentro» de la imagen y se ha limitado tan sólo a estar «delante» de la imagen.

Es el caso de la aberrante traducción española editada para traducir el nombre propio de uno de los animales más importantes en el famoso videojuego The Legend of Zelda. Skyward Sword: ロフトバード (Rofutobādo) en japonés, Loftwing en inglés.

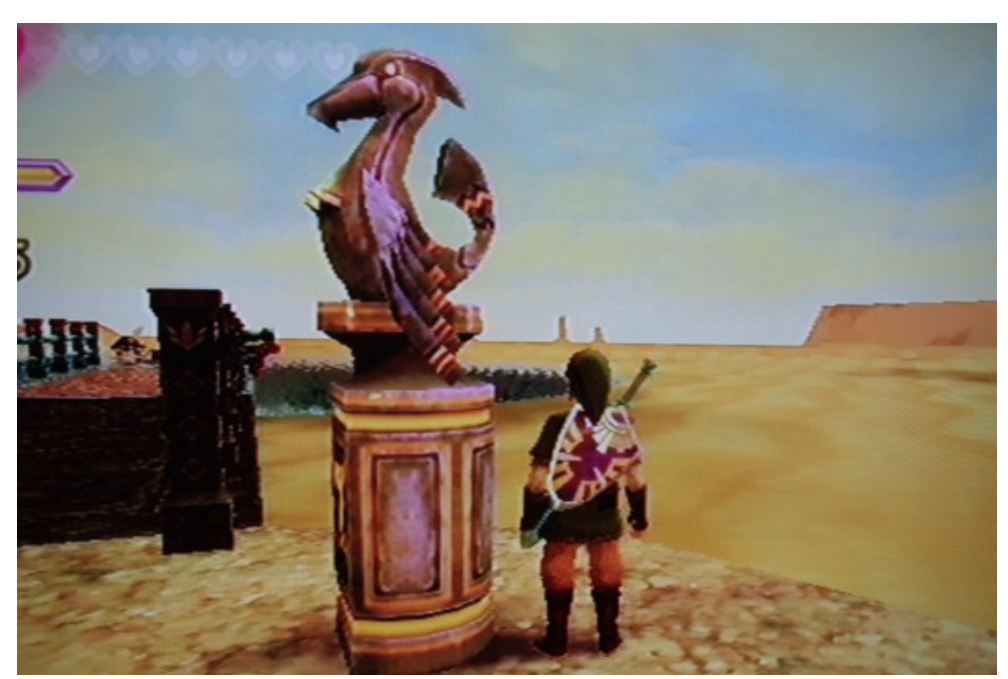

Recordemos que el katakana es un silabario de la escritura japonesa usado para escribir palabras tomadas de otros idiomas (principalmente del inglés en tiempos recientes) así como en onomatopeyas. En katakana, el nombre de Rofutobaado es un anglicismo naturalizado que traduce fielmente al japonés el imaginario construido por las palabras inglesas Loft (Rofuto) y Bird (Baado). La traducción al español editada en España, Pelícaro, rompe la «nobleza» del imaginario que vehiculan los colores espectacularmente dibujados en las enormes «alas sublimes» de este animal. Menos mal que en la edición hispanoamericana el imaginario de ascensión en el vuelo se ha respetado con la traducción al español de Neburis. Muchos jugadores españoles han querido ver en el nombre de Pelícaro una especie de juego de palabras construido por los traductores para hacer referencia al precio caro que se paga por el juego de Nintendo para Wii: «un pelín caro». ¿Acaso el escopo buscado por Nintendo en la traducción del videojuego The Legend of Zelda. Skyward Sword editado en España era hacer provocar la sonrisa del jugador criticando la política de precios de la compañía con el fin de otorgar al comprador un cierto estatus? 
Quedarse «delante» de la imagen y no entrar «dentro» puede hacer pensar que lo más importante del animal en cuestión sea su pico. Pero por mucho que la forma del pico del ave esté inspirada en el picozapato (Shoebill en inglés, balaeniceps rex en latín), un ave de color gris del África tropical y oriental, lo que más destaca en la imagen de Loftwing no es su pico sino sus alas. Dar importancia al pico del ave lleva a traducir Loftwing por Pelícaro al asociarlo en el imaginario occidental con un animal de enorme transcendencia en la simbología cristiana por lo que hace con su pi-

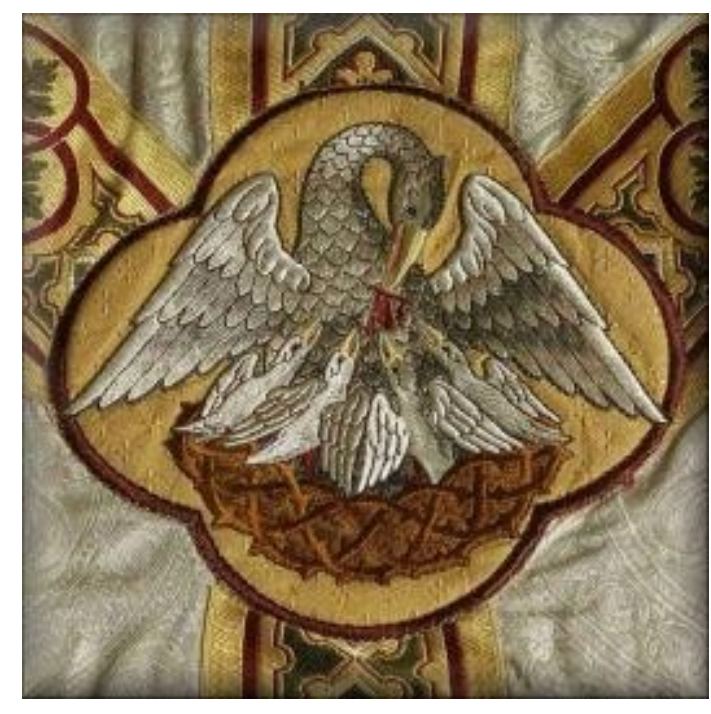
co y cuyo nombre se pronuncia de forma casi idéntica al del animal del videojuego: el «pelícano» (una sola letra de diferencia: «l» frente a «r»). Pelícaro y «pelícano» son parónimos. En efecto, el pelícano adulto, cuando está en su nido, inclina su pico hacia el pecho para alimentar a sus crías con los peces que lleva en la bolsa inferior de su pico. Esta realidad ha llevado durante siglos a la falsa creencia de que el pelícano se desgarra su propio pecho para alimentar a sus crías con su propia sangre. El pelícano se convirtió así en símbolo de la muerte sacrificial de Cristo y de su Resurrección (como lo es el ave Fénix), así como del amor paternal que no retrocede ante ningún sacrificio.

En definitiva, con el nombre de Pelícaro estamos ante un claro ejemplo de cómo haberse quedado «delante» de la imagen y no haberse entrado «dentro» consigue «romper las alas» (Broken Wings) del animal simbólico más importante de The Legend of Zelda. Skyward Sword en la traducción editada en la localización española del videojuego. La función primordial de este animal simbólico en el videojuego no es el sacrificio sino el transporte aéreo: volar de isla a isla, ir por la nubes de mundo a mundo.

\section{Habitar la imagen para-traducir su transformación en los videojuegos}

Lo que siempre llama más la atención del neófito cuando contempla, por primera vez, a un jugador de videojuegos (o a cualquier usuario habitual de un ordenador) es la suma rapidez con la que manipula todo lo que desfila en pantalla. En un videojuego para PC, por ejemplo, un leve desplazamiento milimétrico del ratón y una ligera presión del índice bastan para hacer mover la imagen en el espacio, modificar sus colores o sus texturas, cambiar el punto de vista o iniciar acciones complejas como pueden ser la exploración de una parte de esa imagen en pantalla por parte de un determinado personaje. La capacidad de transformación de la imagen en pantalla que ofrecen los mandos de las distintas consolas de videojuegos es todavía más sorprendente. Todas esas transformaciones provocan en el jugador espacios de familiaridad imprescindibles para crear la sensación de estar «inmerso» en el mundo virtual desplegado por el videojuego. De ahí que no haya videojuego que no repita, una y otra vez, el gesto de estar pasando por los mismos iconos, las mismas imágenes, con el fin de guardar los cambios antes de pasar a cualquier otro 
nivel en la partida. Es justo lo que ocurre con la estatua de Pelícaro en The Legend of Zelda. Skyward Sword. El jugador consigue la familiaridad a base de repeticiones sucesivas de guardar los cambios de la partida ante la estatua de Pelícaro que aparece en el transcurso de cada nivel del videojuego.

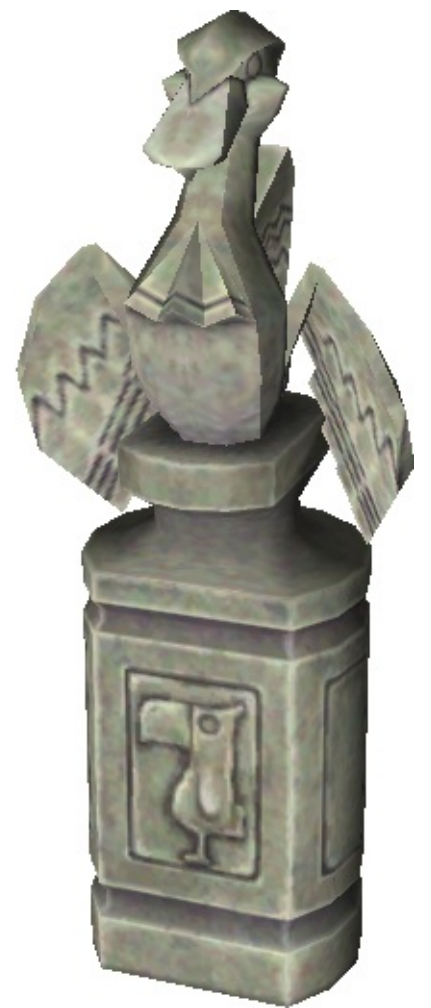

Un factor esencial de la familiaridad en la imagen es su exploración. La exploración de los detalles de una imagen permite conocerla mejor para entrar en ella y habitarla. La localización de videojuegos implica una nueva relación del traductor con la imagen: toda imagen en pantalla es un espacio abierto que nos invita a entrar en ella para explorarla hasta en el más mínimo detalle y dejarse llevar por las sensaciones que procura. Por eso, en todo proceso de localización de videojuegos, el traductor debería tener voz a la hora de elegir cada imagen que conformará el mundo que el jugador de la lengua y cultura de llegada tendrá que explorar a todo color. Al ser el primer agente paratraductor del videojuego que está traduciendo, el traductor es el sujeto que mejor conoce cómo funciona, por ejemplo, la simbología de cada color en la cultura de llegada y, por consiguiente, puede llegar a sugerir que determinados colores sean cambiados para una mayor recepción de la imagen en cuestión. Un traductor no sólo «ve» los colores de una imagen, sino que al «mirar» la imagen percibe los colores de una manera muy determinada según la lengua, la cultura, el momento y el lugar del contexto comunicativo del videojuego según esté editado en la cultura de partida o en la cultura de llegada. Porque cada sociedad tiene su propia percepción diferente de los colores, han existido, existen y existirán sociedades donde se ve el color y el contraste entre colores de manera diferente. Nombrar, designar y connotar los colores no son sólo hechos lingüísticos que cambian de una lengua a otra, sino que son también hechos sociales, culturales e imaginarios diferentes según la localización espacio-temporal. Cada cultura tiene sus colores favoritos, sus propias referencias plásticas que construyen estructuras simbólicas propias de complicidad, de placer o de rechazo. Cada cultura, cada civilización, cada época ha creado su propia simbología de colores y el traductor lee e interpreta los valores simbólicos otorgados a cada color para-traducirlos.

Habitar la imagen resulta ser un acto imprescindible antes de traducir el comportamiento de la misma en el videojuego. Antes de localizar una imagen, el traductor debe vivir su manipulación y su transformación. Si no se explora la imagen habitando todos sus detalles no se puede elegir bien el nombre español de Loftwing para-traducir el imaginario vehiculado por la imagen que representa, anima, manipula y transforma este animal en el videojuego. Si no se habita la imagen antes de traducir, se puede correr el riesgo de que Link caiga del cielo o se quede en las nubes al no saber cómo llamar a Loftwing por mucho que repitamos, una y otra vez, la llamada del silbido con el mando cuando estamos jugando. Y para habitar la imagen nada como jugar al videojuego que se está traduciendo: sólo así se logra encontrar las mejores soluciones de traducción. Hay que saber jugar para traducir videojuegos, así que: ¡A jugar! 


\section{Conclusiones}

Gracias a la noción de paratraducción, la traducción en la localización de videojuegos nunca se reduce a una mera tarea automática consistente en encontrar, lo más rápido posible, equivalencias textuales de un texto lo suficientemente internacionalizado para que, así, casi se traduzca sólo o, si acaso, con la ayuda puntual de una memoria de traducción. Cualquier traductor profesional jamás debería permitir que su trabajo en la localización de productos se reduzca tan drásticamente. Sustituir segmentos textuales adaptándolos de forma deshumanizada es una tarea que menosprecia la labor creativa que implica siempre todo acto de traducción. Con la noción de paratraducción, el Grupo T\&P reivindica el deber de todo traductor/localizador de videojuegos de ocuparse de todas y cada una de las producciones paratextuales que acompañan, rodean, envuelven, prolongan, introducen y presentan el texto audiovisual y multimedia (dentro y fuera de pantalla). La noción de paratraducción revaloriza, en definitiva, los conocimientos culturales sin competencia que posee el traductor profesional a la hora de asegurar el éxito de la traducción de los paratextos en la localización de productos en nuevos mercados.

Desde la perspectiva de la noción de paratraducción como herramienta metodológica para la localización de videojuegos, los videojuegos no son sólo un fenómeno social sino que constituyen la nueva encrucijada en la que se basa la nueva definición de nuestra relación con la imagen. El éxito de cualquier videojuego reside, precisamente, en conseguir la impresión, siempre extraordinaria, de estar «dentro de la imagen». Los videojuegos que triunfan en el mercado son aquellos capaces de transmitir la sensación de estar «inmerso dentro de la imagen» cuando uno juega. El traductor debe demostrar a la compañía de videojuegos que es capaz de leer e interpretar dicha sensación de estar «envuelto por la imagen» para-traducirla en la versión finalmente editada de su traducción. Una excelente traducción de videojuegos es aquella que ha sabido transmitir la sensación de estar «bañado por la imagen» hasta tal punto de que el usuario final no pueda ignorar la invitación de «habitar la imagen».

José Yuste Frías jyuste@uvigo.es Profesor Titular de la Universidade de Vigo, España Grupo de investigación T\&P 


\section{Referencias bibliográficas}

Breton, Philippe L'utopie de la communication, París: La Découverte/Poche, 1997.

CANCIO PASTOR, Carmelo y Sydney BELMONTE (2010) «De la localisation à la délocalisation : enjeux professionnels» Meta, vol. 55, n. ${ }^{\circ}$ 4: 661-673.

Ducrot, Oswald y Tzvetan Todorov (1972) Dictionnaire encyclopédique des sciences du langage, París: Seuil.

Esselink, Bert (1998) A Practical Guide to Software Localization, Amsterdam: John Benjamins.

(2000) A Practical Guide to Localization, Amsterdam: John Benjamins. (2003) «The Evolution of Localization» The Guide to localization, suplemento de Multilingual Computing and Technology, 14 (5): 4-7. (2006) «The Evolution of Localization», en Pym, Anthony, Alexander Perekrestenko y Bram Starink [eds.] Translation Technology and its Teaching, Tarragona: Intercultural Studies Group, pp. 21-30.

GenetTe, Gérard (1982)Palimpsestes, París: Seuil. (1987) Seuils, París: Seuil, col. Points Essais n. ${ }^{\circ} 474$.

GOUADEC, Daniel (2003) «Le baggage spécifique du localiseur/localisateur - le vrai “ nouveau profil ” requis», Meta, vol. vol. 48, n. ${ }^{\circ} 4$ : 526-545.

LEFEVERE, André (1992) Translation, Rewriting and the Manipulation of Literary Frame, London and New York: Routledge.

Niranjana, Tejaswini (1992) Siting Translation. History, Post-structuralism and the Colonial Context, Berkeley/Los Angeles/Oxford: University of California Press.

Niosi, Jorge y F. Ted Tschang (2009) The strategies of Chinese and Indian software multinationals: implications for internationalization theory, Oxford: Oxford University Press.

QUIRION, Jean (2006) «La localisation, palimpseste de l’aménagment terminologique ? Stratégies d’implantation terminologique et marketing», Meta, vol. 51, n. ${ }^{\circ}$ 4: 824-837

PyM, Anthony (2003) «Redefining Translation Competence in an Electronic Age. In Defence of a Minimalist Approach», Meta, vol. 48, n. ${ }^{\circ}$ 4: 481-497. (2004) The Moving Text. Translation, Localization, and Distribution, Ámsterdam y Filadelfia: John Benjamins

(2010) Exploring Translation Theories, Londres y Nueva York: Routledge.

Yuste Frías, José (2005) «Desconstrucción, traducción y paratraducción en la era digital», en Yuste Frías, José y Aberto Álvarez Lugrís [eds.] Estudios sobre traducción: teoría, didáctica, profesión, Vigo: Servizo de Publicacións da Universidade de Vigo, col. T\&P, n. ${ }^{\circ}$ 1, pp. 59-82.

(2010) «Au seuil de la traduction : la paratraduction», en Naaijkens, Ton [ed.] Event or Incident. Événement ou Incident. On the Role of Translation in the Dynamics of Cultural Exchange. Du rôle des traductions dans les processus d'échanges culturels, Bern, Berlin, Bruxelles, Frankfurt am Main, New York, Oxford, Wien: Peter Lang, col. Genèses de Textes-Textgenesen (Françoise Lartillot [dir.]), vol. 3, pp. 287-316. 
(2011a) «Traducir para la pantalla: el traductor entre el texto y la imagen» en Di Giovanni, Elena [ed.] Diálogos intertextuales 5: Between Text and Receiver: Translation and Accessibility. Entre texto y receptor: traducción y accesibilidad, Frankfurt am Main, Berlin, Bern, Bruxelles, New York, Oxford, Wien: Peter Lang, pp. 57-88.

Yuste Frías, José (2011b) «Leer e interpretar la imagen para traducir», Trabalhos em Lingüística Aplicada, vol. 50, n. ${ }^{\circ}$ 2: 257-280. 